\title{
Analisa Teknis dan Ekonomis Automatic Stacking Crane di PT. Terminal Teluk Lamong PELINDO III
}

\author{
Elton K. Silalahi, Sardono Sarwito, dan Adi Kurniawan \\ Jurusan Teknik Sistem Perkapalan, Fakultas Teknologi Kelautan, Institut Teknologi Sepuluh Nopember (ITS) \\ Jl. Arief Rahman Hakim, Surabaya 60111 Indonesia \\ e-mail: sarsan@jurusan.its.ac.id
}

\begin{abstract}
Abstrak- Aplikasi Automatic Stacking Crane sebagai alat angkut atau memindahkan container di pelabuhan telah menjadi obyek penelitian pada beberapa tahun terakhir ini. Ketertarikan ini berdasarkan pertimbangan pada upaya untuk mengurangi polusi udara dan suara yang dihasilkan oleh Rubber Tyred Gantry Crane yang selama ini digunakan. Pada penulisan tugas akhir akan dikaji secara teknis dan ekonomis mengenai perancangan dan operasi Automatic Stacking Crane yang telah digunakan oleh PT. Terminal Teluk Lamong PELINDO III. Kajian teknis meliputi penempatan lokasi, komponen, suplai daya dan transmisi, control crane. Kajian ekonomis meliputi biaya operator, biaya operasional, biaya pemeliharaan, biaya pengadaan, biaya pemasukan, biaya pengeluaran, pelunasan dan aliran kas. Hasil yang diperoleh dari penggunaan Automatic Stacking Crane di pelabuhan adalah Automatic Stacking Crane lebih menjamin keselamatan, rendah getaran, suara, dan emisi, lebih baik mudah dalam kontrol dan monitoring dan lebih baik dalam integrasi data, lebih murah dalam biaya operator, operasional, dan pemeliharaan, dan baik untuk investasi jangka panjang, dimana pada tahun ke-16 aliran kas lebih besar 11,767,574,905 dari pada Rubber Tyred Gantry Crane.
\end{abstract}

Kata Kunci-ASC, Kajian Ekonomis, Kajian Teknis, RTG.

\section{PENDAHULUAN}

$\mathrm{P}$ ELABUHAN adalah salah satu infrastruktur penunjang transportasi laut yang merupakan pintu gerbang keluar masuk barang dan penumpang. Fungsi dan peran pelabuhan sangat penting dalam mendukung sistem transportasi untuk pengembangan suatu wilayah. Terminal kontainer adalah salah satu fasilitas pelabuhan yang digunakan untuk proses bongkar muat barang dalam kontainer. Lamanya proses penumpukan kontainer bergantung pada beberapa faktor, salah satunya adalah kualitas dan kuantitas peralatan yang ada. Rubber tyred gantry crane (RTG crane) adalah suatu alat angkat angkut yang berfungsi untuk memindahkan kontainer dari head truck ke terminal kontainer atau sebaliknya dan sebagai pengatur tumpukan susunan kontainer.

Dalam operasinya, RTG crane/ semi otomatis crane dapat mengangkut beban container berkisar 36 sampai 40 ton dengan kebutuhan listrik rata-rata $300-500 \mathrm{~kW}$ yang disuplay dari generator listrik yg berada di tiap-tiap RTG Crane [1]. Seiring perkembangan teknologi, RTG Crane juga mengalami perkembangan. Listrik yang dipasok ke RTG Crane di pelabuhan bersumber dari PLN dimana RTG Crane ini dinamakan Automatic Stacking Crane, seluruh Auto Stacking Crane pada pelabuhan kelistrikannnya bersumber dari satu sumber yaitu PLN. Perkembangan RTG Crane ini dibuat untuk mengurangi efek polusi dan suara yang dikeluarkan dari mesin diesel oleh RTG Crane.

Oleh sebab penggunaan Auto Stacking Crane, maka pada pelabuhan akan ada perubahan secara teknis, daya dan ekonomis dengan adanya perencanaan pengadaan sistem Auto Stacking Crane. Pada penelitian ini akan dianalisa perbandingan teknis dan ekonomis pada Auto Stacking Crane
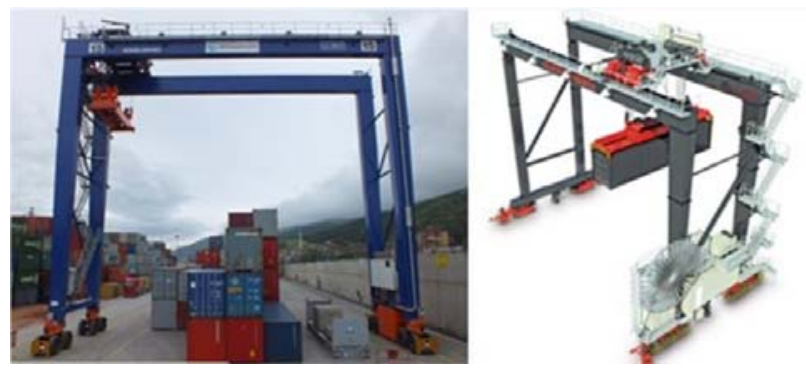

Gambar. 1. RTG dan ASC

terhadap RTG Crane yang menggunakan tenaga diesel.

\section{A. Alat Bongkar Muat}

Peralatan mekanis memindahkan barang bongkaran ataupun muatan dari/ke atas kapal baik peralatan derek/crane kapal maupun peralatan di dermaga atau pelabuhan dibantu forklift dan lifting equipment seperti gantry crane dan peralatan mobile lainnya. Perencanaan alat-alat bongkar muat di terminal terutama barang yang melalui gudang didasarkan pada:

a. Total tonase barang yang dilayani;

b. Tonase barang yang melalui transfer di dermaga;

c. Jenis, berat, ukuran panjang-lebar-tinggi, dan jumlah;

d. Jenis dan tipe kemasan;

e. Manuverability, lifting capacity, traveling speed dan karakteristik peralatan lainnya;

f. Kehandalan dan pelaikan peralatan yang tersedia;

Dalam rencana pengalokasian alat-alat mekanis, faktor keseimbangan anatara output operasi kapal dengan kapasitas armada di terminal adalah kunci penentu kelancaran aktivitas bongkar muat. Hendaknya kapasitas dan mobilitas peralatan terminal mampu melayani dengan seimbang (balance) 
terhadap output kapal. Situsi imbalance harus dapat dicegah.[2].

\section{B. Gantry Crane}

Gantry Crane adalah suatu alat yang digunakan untuk mengangkat atau memindahkan muatan berat dan banyak digunakan di pelabuhan untuk proses loading - unloading container. Dalam Eksitasi internal atau eksternal, payload selalu memiliki kecenderungan untuk berosilasi tentang posisi vertical maupun horisontal, sehingga masalah banyak terjadi pada dinamika dari struktur crane khususnya jenis Gantry dan gerakan pendulum payload. Gerakan yang ditimbulkan oleh pendulum payload menimbulkan beban massa pendulum payload bertambah sehingga menimbulkan ketidakstabilan crane dan kerusakan serius pada sistem crane. Didasarkan kebutuhan kestabilan crane, maka diperlukan analisa kestabilan crane jenis gantry berbasis amplitudo respon getaran agar mendapatkan kestabilan. Dalam lingkungan kita, ada kebutuhan untuk memindahkan hal-hal seperti peralatan dari satu tempat ke tempat lain jauh maupun dekat. Pada suatu industry konstruksi, pelabuhan, kereta api banyak digunakan untuk mengangkut suatu barang biasanya bebannya berat sehingga tidak dapat ditangani oleh pekerja melainkan dibutuhkan bantuan alat agar lebih memudahkan pekerjaan, Crane telah banyak digunakan untuk mengakat maupun memindahkan mesin, alat, container dan benda berat lainnya, ada banyakmacam jenis crane sesuai dengan kebutuhan suatu industry seperti tower crane, overhead crane, mobile crane dan gantry crane.Crane jenis gantry adalah salah satu alat banyak digunakan diarea container yard (Lapangan kontainer) sedang mobile crane biasa digunakan untuk memindahkan muatan diatas kapal ke daratan pelabuan. Gantry crane terdiri dari pendulum, payload, crane mempunyai aturan bagaimana prosedur mengangkat suatu container, ada sebuah kabel dengan payload menggantung dan pendulum akan bergerak mengangkat maupun menurunkan beban ke lokasi yang dinginkan. Penanganan Gantry crane, keselamatan adalah poin yang paling penting untuk dipertimbangkan saat operasi gantry crane. Oleh karena itu, Gantry crane dioperasikan dengan mengikuti SOP (Standart Operation Prosedure) untuk meminimalisasikan tingkat kecelakaan yang diakibatkan operasional gantry crane maka prosedur sangat dibutuhkan, adapun antara lain :

a. Sebelum gantry crane dioperasikan hendaknya beban payload diperiksa apakah sudah memenuhi toleransi agar beban tidak melebihi load maksimum yang dimiliki gantry crane.

b. Kegiata operasi harus diawasi oleh tenaga kerja yang profesional.

c. Operator gantry crane harus terbiasa mengoperasikan alat tersebut.

Operator harus memiliki keahlian mengoperasikan alat dan agar dapat mengoperasikan alat dengan baik, maka setiap bulan operator akan dilatih.

Faktor-faktor lain juga harus dipertimbangkan sehingga kemungkinan kecelakaan terjadi adalah kecil . Ada banyak faktor yang harus dipertimbangkan, sistem pengereman, komponen hidrolik dan pneumatik, listrik peralatan, alat bantu operasional, mekanisme operasional, mengangkat perangkat, menentukan beban berat, segera mengenali bahaya dan potensi, sistem kontrol dan lain-lain. Jangka waktu sistem kontrol, isu penting adalah bagaimana untuk mengontrol beban ayunan. Ini penting untuk memiliki operasi yang lebih cepat dengan tetap menjaga keamanan Kendaraan beroda secara umum, crane dapat didefinisikan sebagai mesin yang digunakan untuk mengangkat dan menurunkan sebuah beban vertikal dan bergerak secara horisontal dan yang memiliki mekanisme mengangkat sebagai bagian integral.[3].

\section{Automatic Stacking Crane}

Jika sekarang kita kenal alat angkat dan angkut Rubber Tyred Gantry (RTG), maka untuk terminal modern saat ini menggunakan alat yang dikenal dengan nama Automatic Stacking Crane (ASC). Kegunaan ASC sama persis dengan RTG, yang membedakan adalah ASC tidak lagi dioperasikan oleh operator di atas alat, melainkan dari ruang kontrol gedung kantor.

Sumber daya manusia saat ini bagi perusahaan sudah menjadi aset yang tidak murah. ASC memberikan solusi atas mahalnya biaya operator dengan :

a. Tidak menggunakan operator di atas alat, jadi dari segi keselamatan lebih bagus karena di lapangan penumpukan peti kemas nanti sama sekali tidak ada operator.

b. Produktivitas alat bisa 2 kali lebih tinggi daripada RTG3. Biaya perawatan dan operasional lebih hemat $30-40 \%$ karena 1 operator bisa mengoperasikan 4-6 alat secara bersamaan.

c. ASC ini menggunakan menggunakan tenaga listrik yang disuplai dari PLN sehingga tidak ada emisi gas buang memberikan predikat alat yang ramah lingkungan. Karena menggunakan tenaga listrik, alat tersebut lebih hemat bahan bakar 30-50\% dari pada RTG yang menggunakan mesin diesel.

d. Tidak menggunakan sistem hidrolis sehingga pemeliharaannya lebih mudah.

e. Intelligent Structure membuat pergeseran dan kerja alat menjadi lebih ringan karena struktur crane didesain lebih kokoh tapi ringan. [4].

\section{METODE PENELITIAN}

A. Umum

Metodologi tugas akhir merupakan urutan sistematis tahapan pengerjaan tugas akhir yang dilakukan sejak dimulainya pengerjaan hingga akhir. Penulisan tugas akhir ini 
bersifat penelitian sehingga dibutuhkan data-data riil untuk mendukung pelaksanaan penelitian. Metodologi yang digunakan penulis dalam melakukan penelitian ini secara umum dimulai dengan identifikasi permasalahan, penentuan kapal yang akan digunakan sebagai objek penelitian, studi literature, pengumpulan data, analisa teknis dan ekonomis Automatic Stacking Crane, membandingkan dengan sistem Rubber Tyred Gantry Crane bertenaga diesel, analisa pembahasan, evaluasi, dan diakhiri kesimpulan dan saran.

\section{B. Identifikasi dan Perumusan Masalah}

Merupakan tahapan awal yang dilakukan dalam melakukan penelitian sehingga diketahui masalah apa yang akan diangkat. Dalam penulisan tugas akhir ini permasalahan yang diambil adalah sistem penumpukan crane di pelabuhan yang lebih ramah lingkungan dan serba otomatis dengan fokusan masalah pada efisensi dan biaya yang akan dikeluarkan dalam merencanakan sistem penumpukan crane tersebuat.

\section{Studi Pustaka}

Pada tahapan ini dilakukan pembelajaran terhadap teoriteori yang mendukung penelitian dan akan dibahas dalam penulisan tugas akhir. Teori yang dimaksud terkait peralatan penumpukan crane di pelabuhan, keselamatan kerja, dan emisi gas buang peralatan mesin di pelabuhan. Sumber yang digunakan sebagai acuan dapat berasal dari buku, jurnal, paper dan Internet.

\section{Pengumpulan Data}

Pengumpulan data bertujuan untuk mendapatkan informasi terkait permasalahan yang akan dibahas dalam penulisan tugas akhir ini sehinga dibutuhkan studi lapangan dalama

pengumpulan data. Adapun jenis data yang akan dikumpulkan pada tahap ini antara lain :

a. Data spesifikasi Automatic Stacking Crane

b. Data spesifikasi Rubber Tyred Gantry Crane

c. Biaya investasi dan operasional.

\section{E. Analisa Teknis}

Pada tahapan ini akan dibahas tentang analisa secara teknis peralatan Automatic Stacking Crane dan operasionalnya, Adapun yang akan dianalisa adalah:
a. Lokasi
b. Komponen
c. Suplai daya dan Transmisi
d. Kontrol

\section{F. Analisa Ekonomis}

Pada tahapan ini dilakukan perhitungan biaya investasi dan operasional pada Automatic Stacking Crane. Sehingga diketahui perkiraan biaya instalasi Automatic Stacking Crane ini pada pelabuhan. Adapun biaya-biaya yang akan dihitunga adalah:
a. Biaya operator
b. Biaya operasional
c. Biaya pemeliharaan
d. Biaya pengeluaran

e. Biaya pemasukan

f. Biaya pengadaan

g. Pay back/pelunasan

h. Aliran kas

\section{G. Analisa dan Pembahasan}

Untuk mengetahui keuntungan dan kerugian penggunaan alat Automatic Stacking Crane maka dilakukan analisa dan pembahasan berupa perbandingan data terhadap penggunaan Rubber Tyred Gantry Crane bertenaga diesel.

\section{H. Kesimpulan dan Saran}

Setelah dilakukan proses analisa dan pembahasan, selanjutnya menarik kesimpulan dari hasil penelitian. Kesimpulan berdasarkan dari hasil analisa data dan pembahasan yang telah dilakukan. Selanjutnya adalah memberikan saran-saran yang diberikan sebagai masukan dan bahan pertimbangan pihak yang berkaitan untuk melakukan analisa lebih lanjut

\section{ANALISA DATA}

\section{A. Analisa Teknis}

Automatic stacking crane membutuhkan perencanaan lokasi yang lebih khusus daripada RTG crane dikarenakan ASC harus berada dekat gedung control dan cubicle power PLN, sedangkan RTG tidak membutuhkan lokasi khusus:

ASC memiliki 4 komponen utama yang tidak dimiliki RTG yaitu Cable reel, electrical room, transformator dan bogies, sedangkan RTG memiliki 3 komponen utama yang tidak dimiliki ASC yaitu generator,operator room, dan ban karet, karena memiki generator tentunya RTG akan menghasilkan getaran, suara dan emisi gas buang yang lebih besar daripda

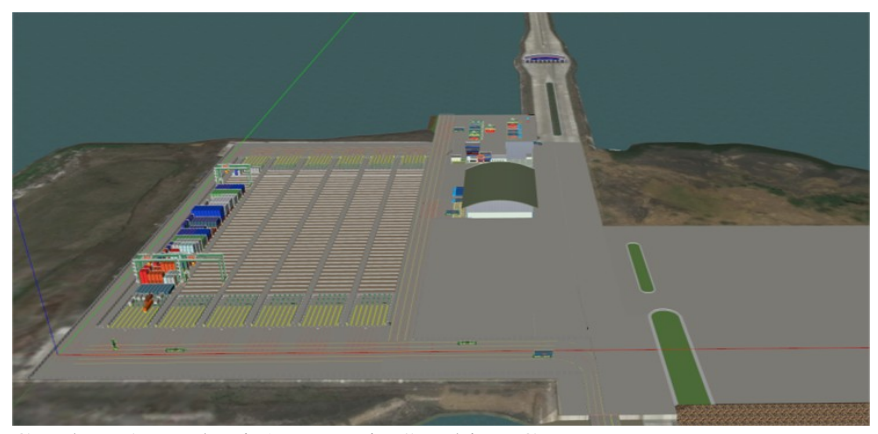

Gambar. 2. Lokasi Automatic Stacking Crane

ASC, karena RTG memiliki operator room di crane, ASC lebih menjamin keamanan operator yang mana operator berada terpisah dari crane yaitu gedung control, dan karena ASC memiliki roda besi yang terpasang di jalur rel maka laju crane lebih akurat tetapi tidak flexible seperti RTG

Suplai daya RTG lebih sederhana dan flexible daripada ASC, RTG memiliki generator pada tiap crane yang kan menyupai daya maka sistem suplai daya RTG tidak begitu rumit dan ini memungkinkan RTG bisa bergerak lebih flexible, sedangkan ASC mendapatkan suplai daya dari PLN 
yang membutuhkan cubicle-cubicle power serta kabel yang panjang untuk transmisi daya ke crane, karena dihubungkan dengan crane ini akan mengurangi flexibilitas crane dan ASC juga harus mempunyai rel tersendiri sebagai jalur crane.

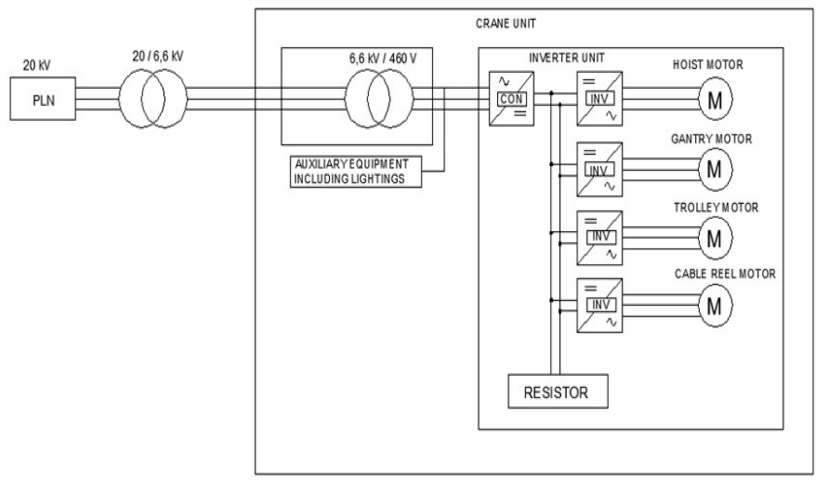

Gambar. 3. Single Line Diagram ASC

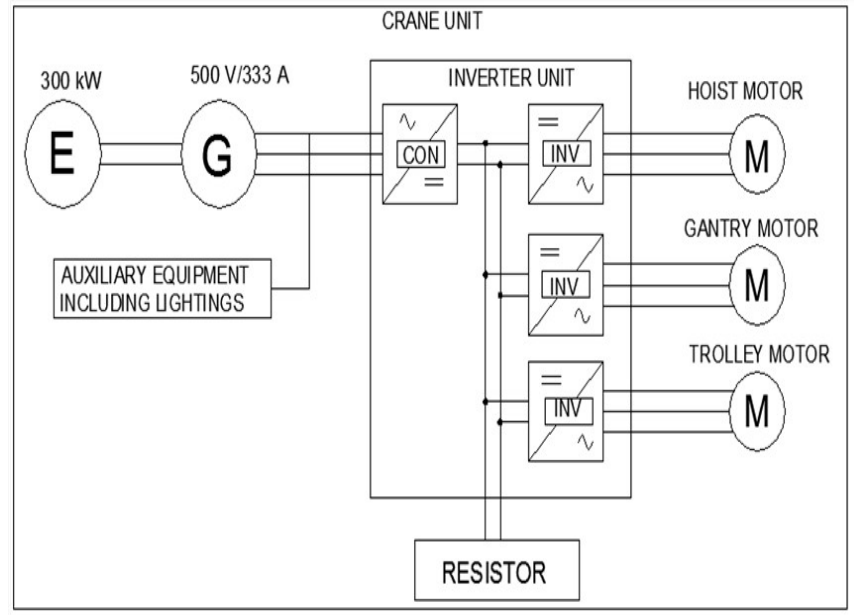

Gambar. 4. Single Line Diagram RTG

Control crane pada RTG lebih sederhana dibanding dengan ASC, tetapi untuk integrasi data, ASC lebih baik daripada RTG, ASC memiliki sistem control Automatic saat dimulai container masuk ke area penumpukan, semua data informasi dari pelabuhan dan lokasi penumpukan crane diolah sedemikan rupa secara otomatis yang memungkinkan operator hanya memantau pergerakan crane dan semua data pemindahan dan penumpukan crane tercatat secara otomatis, sedangkan control RTG dilakukan dengan manual oleh operator yang berada di atas crane, ini memungkin kesalahan manusia/human error lebih sering terjadi.

\section{B. Analisa Ekonomis}

Biaya operator ASC lebih murah dibanding RTG dikarenakan ASC hanya memilik 6 operator setiap harinya dibanding RTG yang menggunakan 20 orang setiap harinya untuk 10 crane.

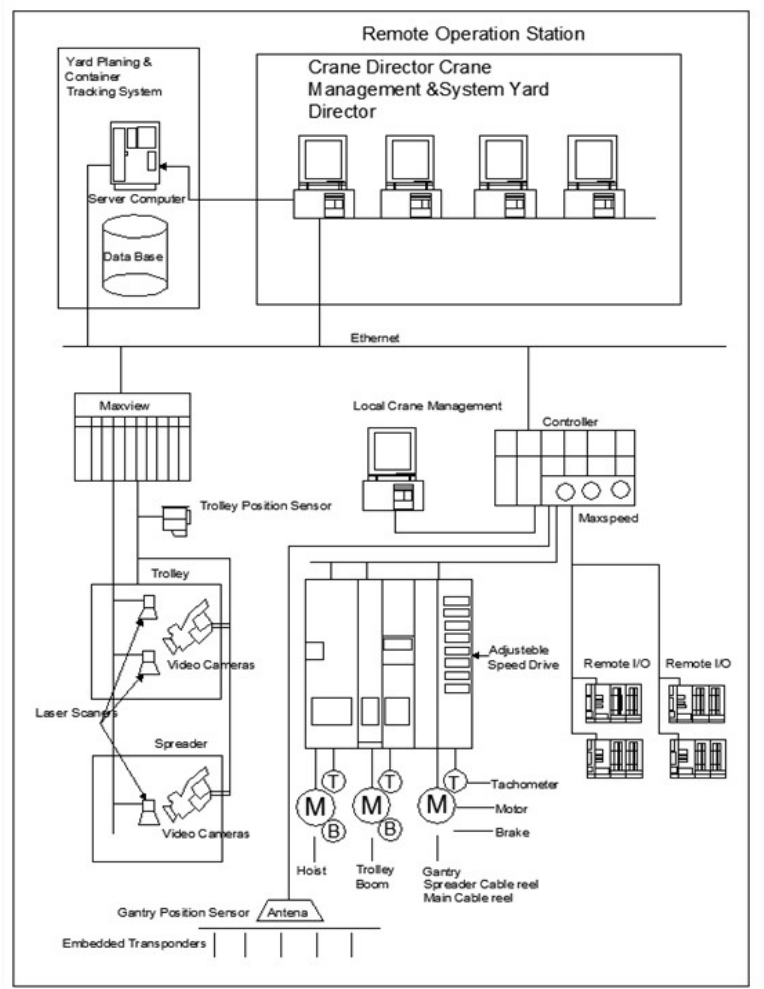

Gambar. 5. Diagram Kontrol ASC

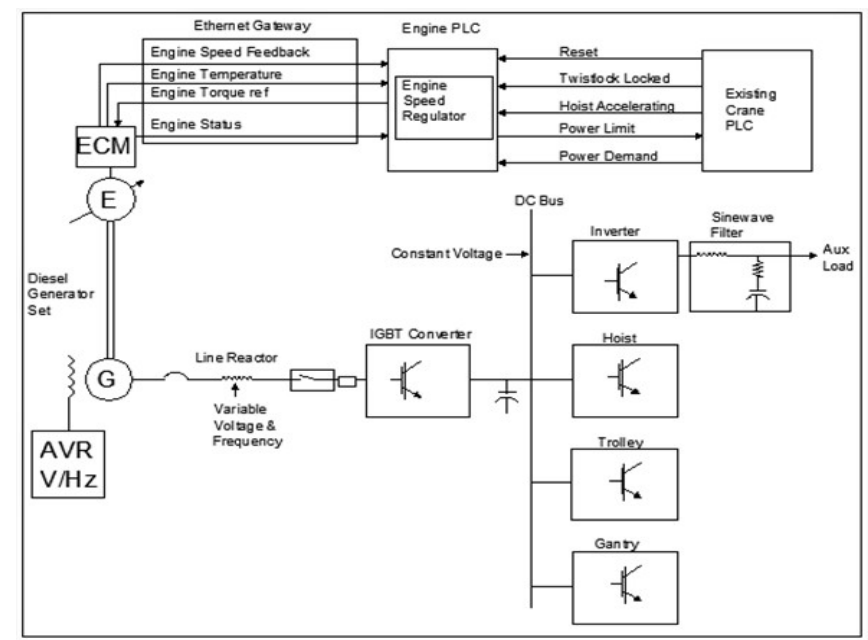

Gambar. 6. Diagram Kontrol RTG

Biaya operasional ASC lebih murah dibanding RTG dikarenakan biaya solar dan pelumas yang dibutuhkan RTG sedangkan ASC hanya konsumsi kelistrikan dari PLN.

Biaya pemeliharaan ASC lebih murah dibanding RTG karena RTG memiliki ban karet dan generator yang rutin harus dirawat sedangkan pada ASC hanya di perlukan perawatan trafo.

Karena biaya operator ASC, biaya operasional ASC, dan biaya pemeliharaan ASC lebih murah, maka pengeluaran ASC lebih murah tiap tahunnya dari pada RTG 
Karena biaya pengeluaran ASC tiap tahunnya lebih murah, maka biaya pemasukan ASC lebih banyak dari pada RTG. Berdasarkan analisa perhitungan biaya pengeluaran dan pemasukan, maka diketahui proses pelunasan/pay back ASC lebih lama setahun dari pada RTG. ASC lebih menguntungkan dari pada RTG terjadi dimulai pada tahun ke 16 dan seterusnya.

\section{KESIMPULAN}

Berdasarkan analisa teknis, lokasi penempatan Automatic Stacking Crane (ASC) di pelabuhan harus berlokasi khusus dan dekat dengan gedung control dan cubicle power dari PLN, lebih rendah getaran, suara, dan tidak menghasilkan emisi gas dikarenakan tidak memilik generator seperti Rubber Tyred Gantry Crane (RTG Crane), lebih menjamin keselamatan operator, karena operator berada di dalam gedung control, bukan di atas crane, memiliki jalur rel sendiri yang mengakibatkan akurasi jalur yang lebih baik tetapi mengurangi flexibilitas, lebih rumit dalam transmisi daya dikarenakan daya bersumber dari PLN yang membutuhkan instalasi khusus, lebih mudah dalam mengontrol dan memonitoring crane karena dibantu beberapa sensor, dan integrasi data yang lebih baik.

Pada analisa ekonomis, Automatic Stacking Crane (ASC) lebih murah untuk biaya operator sebesar Rp.259.200.000 di tahun pertama , operasional sebesar Rp.36,042,715,800 di tahun pertama, pemeliharaan sebesar Rp. 331,778,000 di tahun pertama, memiliki pengeluaran yang sedikit sebesar Rp.38,452,418,490 setelah setahun beroperasi dan pemasukan yang banyak sebesar Rp. 131,453,181,510 setelah setahun beroperasi.

Berdasarkan analisa ekonomis, Automatic Stacking Crane (ASC) lebih lama dalam tahun pelunasan yaitu pada tahun yang ke 4 tetapi lebih baik untuk investasi jangka panjang karena setelah tahun ke 16, aliran kas lebih banyak $11,767,574,905$.

\section{SARAN}

1. Mengkaji penggunaan Automatic Stacking Crane pada berbagai pelabuhan di Indonesia.

2. Melakukan riset pasar untuk mendapatkan harga pengadaan Automatic Stackin Crane yang lebih murah.

\section{DAFTAR PUSTAKA}

[1] Maslufi, Andita Yoggi. 2012. Studi Pemanfaatan rugi daya pada rubber tyred ganty crane saat proses bongkar muat di PT. Terminal Peti Kemas Surabaya. Digilib ITS.

[2] Drs. Daryanto.1992.Alat Pesawat Pengangkut. Cirebon.Rineka Cipta

[3] www.digilib-its.ac.id/ITS-Undergraduate-16520-2408100502 (diakeses 12/31/20015, 18:00 wib)

[4] www.majalah.dermaga.com/crane-semi-otomatis (diakses 12/31/2015, 20:00 wib) 